\title{
O BOM PROFESSOR ENFERMEIRO: o olhar dos estudantes de cursos técnicos acerca da prática docente
}

\author{
Luís Fernando Rampellottil \\ Roberta Pasqualli2
}

\section{RESUMO}

A importância da formação do Técnico em Enfermagem está diretamente relacionada à complexidade do seu ofício, especialmente no que diz respeito ao cuidado com a vida humana. Apesar disso, o Enfermeiro que leciona na educação profissional é formado, majoritariamente, em cursos de Bacharelado e não em Licenciaturas, que são os cursos destinados à formação inicial de professores. Nessa direção, o objetivo deste texto é apresentar, a partir do olhar dos estudantes dos cursos Técnicos em Enfermagem, do município de Joinville - SC o que se chamou de bom professor enfermeiro. Discutem-se categorias relacionadas aos saberes docentes e às práticas educativas desse professor. A metodologia utilizada foi de abordagem qualitativa, do tipo descritiva, com dimensão exploratória. Como resultados, destaca-se que os professores foram apontados como produtores de saberes a partir de seu ofício cotidiano e, nesse sentido, a experiência e o exercício da profissão, quer seja da docência ou da prática da Enfermagem empoderam a tomada de decisões didático-pedagógicas dos professores. Os estudantes apontam, como saberes fundamentais ao exercício da docência do bom professor enfermeiro, aspectos relacionados ao saber fazer, ao saber ser, ao saber agir e aos saberes específicos da docência. Para eles, o bom professor enfermeiro inspira, motiva, estimula e compartilha responsabilidades. Atitudes como dedicação e abertura de espaços para retirar dúvidas e recuperar dificuldades de aprendizado, abertura às demandas dos estudantes, ética e as relações que o professor estabelece entre os conteúdos e o exercício da profissão também foram apresentadas.

Palavras-chave: Práticas Docentes. Enfermagem. Ensino.

1 Mestrado em Educação Profissional e Tecnológica. Professor da Sociedade Educacional de Santa Catarina (UniSociesc), Joinville, SC, Brasil. Orcid iD: https://orcid.org/0000-0002-0346-8747. E-mail: Ivis.rampellotti@gmail.com

2 Doutorado em Educação. Professora do Programa de Pós-Graduação em Educação Profissional e Tecnológica, do Instituto Federal de Educação, Ciência e Tecnologia de Santa Catarina (IFSC), Florianópolis, SC, Brasil. Orcid iD: https://orcid.org/00000001-8293-033x. E-mail: roberta.pasqualli@ifsc.edu.br 


\section{THE GOOD NURSING TEACHER: the view of technical course students about teaching practice}

\section{ABSTRACT}

The importance of the Nursing Technician's training is directly related to the complexity of their profession, especially in regard to caring for human life. Nevertheless, the nurse who teaches in professional education is mainly trained in Bachelor courses and do not hold Licentiate degrees, which are courses for the initial training of teachers. In this direction, the objective of this text is to present, from the perspective of students from Technical Nursing courses in the city of Joinville - SC, what was termed a good nurse teacher - discussing categories related to teaching knowledge and educational practices of this professional. The methodology used was a qualitative approach, of a descriptive type, with an exploratory dimension. As a result, it is noteworthy that teachers were appointed as producers of knowledge from their daily work and, in this sense, the experience and exercise of the profession, whether in teaching or nursing practice, empower teachers; didactic-pedagogical decision-making. The students point out, as fundamental knowledge to the teaching practice of the good Nurse Teacher, aspects related to knowing how to do, knowing how to be, knowing how to act and the specific knowledge of teaching. For them, the good nurse teacher inspires, motivates, encourages and shares responsibilities. Attitudes such as dedication and opening spaces to clarify doubts and deal with learning issues, openness to student demands, ethics and the relationships that the teacher establishes between the contents and the practice of the profession were also presented.

Keywords: Teacher practice. Nursing. Teaching.

\section{EL BUEN PROFESOR DE ENFERMERÍA: la visión de los estudiantes del curso técnico sobre la práctica docente}

\section{RESUMEN}

La importancia de la formación del Técnico de Enfermería está directamente relacionada con la complejidad de su profesión, especialmente con respecto al cuidado de la vida humana. A pesar de eso, la enfermera que enseña en educación profesional se capacita principalmente en cursos de bachillerato (grado superior) y no en títulos de licenciatura, que son los cursos para la formación inicial de los maestros. En esta dirección, el objetivo de este texto es presentar, desde la perspectiva de los estudiantes de los cursos de Enfermería Técnica en la ciudad de Joinville - SC, lo que se llama un buen profesor enfermero. El artículo discute categorías relacionadas con el conocimiento de la enseñanza y las prácticas educativas de este tipo de profesor. La metodología utilizada fue un enfoque cualitativo, de tipo descriptivo, con una dimensión exploratoria. Como resultado, es digno de mencionar que los profesores fueron designados como productores de conocimiento de su trabajo diario y, en este sentido, la experiencia y el ejercicio de la profesión, ya sea en la enseñanza o en la práctica de enfermería, empoderan la toma de decisiones didácticas pedagógicas. Los estudiantes señalan, como conocimiento fundamental para la práctica docente del buen enfermero profesor, 
aspectos relacionados con saber cómo hacer, saber cómo ser, saber cómo actuar y el conocimiento específico de la enseñanza. Para ellos, el buen enfermero profesor inspira, motiva, estimula y comparte responsabilidades. También se presentaron actitudes como la dedicación y la apertura de espacios para eliminar dudas y recuperar dificultades de aprendizaje, la apertura a las demandas de los estudiantes, la ética y las relaciones que el profesor establece entre los contenidos y el ejercicio de la profesión.

Palabras clave: Práctica Docente. Enfermería. Educación.

\section{INTRODUÇÃO}

A Enfermagem representa, atualmente, o maior contingente de profissionais da área da saúde no país. De acordo com informações do Conselho Federal de Enfermagem (COFEN), até dezembro de 2019 existiam, no Brasil, um total de 2.243.278 profissionais da área de Enfermagem. Desses profissionais, 61.133 estão no estado de Santa Catarina e 40.631 são Técnicos em Enfermagem, foco do estudo apresentado neste texto. (COFEN, 2020).

De acordo com a legislação específica, observa-se que, além da responsabilidade sobre a equipe de enfermagem, o Enfermeiro incorporou à sua prática gerencial e assistencial o exercício do ensino e a direção das escolas de formação profissional, bem como a formação continuada de seus pares, já que, de acordo com o Art. $9^{\circ}$ da Lei n 50.387, de 28 de março de 1961, são atribuições dos Enfermeiros: [...] "b) participação no ensino, Escolas de Enfermagem e de Auxiliar de Enfermagem e treinamento de pessoal em serviço; c) direção e inspeção de Escolas de Enfermagem e de auxiliar de Enfermagem;" [...] (COREN, 2013). Portanto, a habilitação para a ałuação docente na formação profissional de Enfermagem está implicada ao ser Enfermeiro.

Sabe-se, entretanto, que a formação universitária do Enfermeiro ocorre, majoritariamente, em cursos de Bacharelado, disparidade verificada no cadastro de cursos de nível superior do Sistema de Regulação do Ensino Superior (e-MEC), havendo, até agosto de 2019, 1.156 cursos de Bacharelado em Enfermagem e somente 12 cursos de Licenciatura em Enfermagem em atividade no Brasil (BRASIL, 2019).

Os egressos do curso de Bacharelado, embora legalmente habilitados

Revista Exitus, Santarém/PA, Vol. 10, p. 01-28, e020027, 2020. 
para as atividades de ensino em Enfermagem, não alcançam, na graduação, os saberes próprios às licenciaturas. Assim, embora muitos desses ingressem na docência de Cursos Técnicos em Enfermagem, a formação de base foi voltada para a atuação assistencial e/ou gerencial, privando-lhes de conhecimentos didáticos/pedagógicos/metodológicos, fundamentais para o exercício da docência (SGARBI, 2015).

Sobre esses aspectos, questionam-se quais são os saberes necessários ao ensino dessa profissão e, nessa direção, destaca-se o pensamento de Tardif (2010), ao indagar se os conhecimentos mobilizados pelos professores em seu ofício cotidiano são: "[...] conhecimentos técnicos, de saberes da ação, de habilidades de natureza artesanal adquiridas através de uma longa experiência de trabalho? [...]" (TARDIF, 2010, p. 6).

Um estudo desenvolvido por Sgarbi et al. (2015) sugere que esses profissionais não apresentam um saber docente específico sob a ótica de não serem docentes por formação. Contudo, apresentam saberes que movimentam sua atuação e estão relacionados à própria prática. Esses saberes contribuem e fundamentam as interações humanas que estes realizaram e sofreram em sua própria fase formativa de base, bem como, as experiências pessoais e profissionais.

Para Tardif (2010), a aquisição dos saberes dos professores constitui [...] "um processo em construção ao longo de uma carreira profissional na qual o professor aprende progressivamente a dominar o seu ambiente de trabalho, [...] e o interioriza [...] se tornam parte integrante de sua 'consciência prática'" (TARDIF, 2010, p. 14).

De acordo com Arroyo (2000), o professor necessita compreender o real significado da sua profissão:

Teríamos que conseguir que os outros acreditem no que somos. Um processo social complicado, lento, de desencontros entre o que somos para nós e o que somos para fora [...] Somos a imagem social que foi construída sobre o ofício de mestre, sobre as formas diversas de exercer este ofício. Sabemos pouco sobre a nossa história (ARROYO, 2000, p. 29).

Nessa direção, é na busca pelo 'bom professor enfermeiro', a partir do 
Olhar dos estudantes dos Cursos Técnicos em Enfermagem, do município de Joinville - SC, identificando os saberes docentes marcantes e como esses saberes se materializam na prática dos bons Professores Enfermeiros que este estudo se concretiza.

No Estado de Santa Catarina, locus da pesquisa, existem 110 escolas inscritas no Sistema Nacional de Informações da Educação Profissional e Tecnológica (SISTEC), com destaque para as cidades de Joinville, com 11 escolas, Florianópolis, com 09 escolas e Blumenau e Palhoça, com 05 escolas (BRASIL, 2019).

Para a realização desta pesquisa, optou-se pela investigação com estudantes dos Cursos Técnicos em Enfermagem, do município de Joinville SC, por três motivos: (a) ser o maior centro de formação de profissionais da área de Enfermagem do Estado de Santa Catarina; (b) o pesquisador ser Professor Enfermeiro neste município e (c) a necessidade de elaboração e aplicação de um produto educacional destinado à prática docente do pesquisador, requisito para a obtenção do título de Mestre em Educação Profissional e Tecnológica.

Subsidiado pela literatura da área, especialmente pelos estudos de autores, como Barato (2015), Cunha (2012), Freire (2018), Libâneo (2012), Sgarbi (2015), Pimenta (2013) e Tardif (2010) este texto está organizado em quatro partes. A primeira parte apresenta a introdução, elencando, dentre outros, as motivações para a realização da pesquisa, a segunda, os aspectos metodológicos, a terceira, os resultados e as discussões e, por fim, apresentam-se as considerações finais.

\section{METODOLOGIA}

Antes de mais nada, recorre-se a Álvaro Vieira Pinto (2005), compreendendo o caráter histórico antropológico da educação. Foi a partir dessa compreensão que toda a pesquisa desenvolveu-se.

De acordo com Pinto (2005): 
(a formação do homem) no tempo, ou seja, é um fato histórico. A educação é um fato existencial. Refere-se ao modo como (por si mesmo e pelas ações exteriores que sofre) o homem se faz ser homem. A educação configura o homem em toda a sua realidade. A educação é um fato social. Refere-se a sociedade como um todo. É determinada pelo interesse que move a comunidade a integrar todos os seus membros à forma social vigente (relações econômicas, instituições, usos, ciências, atitudes, etc.). A educação é um fenômeno cultural. A educação se desenvolve sobre o fundamento do processo econômico da sociedade. A educação é uma atividade teleológica. A formação do indivíduo sempre visa a um fim. A educação é uma modalidade de trabalho social. A educação é um fato de ordem consciente. A educação é um processo exponencial, isto é, multiplica-se por si mesma com sua própria realização. A educação é por essência concreta. Pode ser definida a priori, mas o que a define é sua realização objetiva, concreta. A educação é por natureza contraditória, pois implica simultaneamente conservação (dados do saber adquirido) e criação (PINTO, 2005, p. 30-34).

Partindo do que se apresentou anteriormente, o estudo, de abordagem qualitativa, caracterizou-se como uma pesquisa do tipo descritiva, com dimensão exploratória tendo por base os trabalhos de Yin (2005).

A pesquisa foi realizada com estudantes dos Cursos Técnicos de Enfermagem ofertados em duas instituições de educação profissional do município de Joinville - SC: o Instituto Federal de Educação, Ciência e Tecnologia de Santa Catarina (IFSC) e o Serviço Nacional de Aprendizagem Comercial (SENAC). As instituições assinaram cartas de autorização para a realização da pesquisa que também foi submetida à Plataforma Brasil e aprovada por Comitê de Ética.

A escolha por essas instituições está relacionada à expressiva oferta de Cursos Técnicos em Enfermagem. De acordo com a consulta pública das escolas e cursos técnicos regulares nos sistemas de ensino e cadastrados no MEC (SisTEC), no Estado de Santa Catarina essas duas instituições de ensino dividem a posição de maiores ofertantes de Cursos Técnicos em Enfermagem com o Centro de Educação Profissional (CEDUP) e o Centro de Ensino Técnico Visão (CETEVI), entretanto, no município de Joinville - SC somente o SENAC e o IFSC possuem unidades de ensino (BRASIL, 2019).

A pesquisa foi realizada no mês de junho de 2018 e a amostra de 
sujeitos investigados foi constituída por 34 estudantes, com média de 30 anos.

Os sujeitos da pesquisa foram os estudantes dos Cursos Técnicos em Enfermagem das referidas instituições de ensino, da penúltima e última fase/módulo de formação, uma vez que os pesquisadores entenderam que, nesse momento, os estudantes já teriam tido contato com a maioria dos Professores Enfermeiros de seu curso.

A coleta de dados deu-se pela aplicação de questionário estruturado em duas partes, sendo a primeira de caracterização dos participantes a partir de questões objetivas e discursivas e, a segunda, também com questões objetivas e discursivas, destinada a reconhecer os saberes e as práticas dos bons Professores Enfermeiros, a partir do olhar dos estudantes dos Cursos Técnicos em Enfermagem.

$O$ instrumento de coleta de dados foi elaborado com base na literatura da área e, a fim de verificar sua clareza e validade para o objetivo proposto, antes de sua aplicação foi realizado um pré-teste.

Para a análise dos dados, as respostas foram transcritas e os participantes identificados pela letra ' $A$ ' de aluno. Cada aluno possuiu um número, em ordem crescente, iniciado a partir de '01' para complementação da identificação. Foi realizado o agrupamento temático das respostas correspondentes a cada questão do questionário, criando-se, assim, as categorias de análise.

$\mathrm{Na}$ análise dos dados coletados buscou-se identificar três fatores como orienta Yin (2005), a saber: fatores comuns a todos os casos, fatores não comuns a todos os casos e fatores únicos.

A discussão ocorreu a partir da aproximação teórica entre as proposições dos autores e os achados de estudos semelhantes. Algumas falas dos estudantes foram destacadas e figuram no texto corroborando a discussão dos achados com as proposições de outros autores. 


\title{
RESULTADOS E DISCUSSÕES
}

Para o exercício da profissão docente, como em qualquer outra profissão, é fundamental a existência de saberes. Para a construção dos saberes da docência, Tardif $(2010$, p. 15) destaca que o:

\begin{abstract}
professor se serve de sua cultura pessoal, que provém de sua história de vida e de sua cultura escolar anterior, também se apoia em certos conhecimentos disciplinares adquiridos na universidade, assim como certos conhecimentos didáticos e pedagógicos oriundos de sua formação profissional, ele se apoia também naquilo que podemos chamar de conhecimentos curriculares veiculados pelos programas, guias e manuais escolares, ele se baseia em seu próprio saber ligado a experiência de trabalho, na experiência de certos professores e em tradições peculiares ao ofício de professor (TARDIF, 2012, p.15).
\end{abstract}

Nessa direção, para Tardif (2012, p. 36), o saber docente é "[...] como um saber plural, formado pelo amalgama, mais ou menos coerente, de saberes oriundos da formação profissional e de saberes disciplinares, curriculares e experienciais". E, ainda,

os saberes que servem de base para o ensino são, aparentemente, caracterizados por aquilo que se pode chamar de sincretismo [...] um professor não possui habitualmente uma só e única 'concepção' de sua prática, em função, ao mesmo tempo, de sua realidade cotidiana e biográfica e de suas necessidades, recursos e limitações (TARDIF, 2012, p. 65).

Nóvoa (1995) contribui com essa discussão quando afirma que:

A formação não se constrói por acumulação (de cursos, de conhecimentos ou de técnicas), mas sim através de um trabalho de reflexividade crítica sobre as práticas e de (re)construção permanente de uma identidade pessoal. Por isso é tão importante investir a pessoa e dar um estatuto ao saber da experiência (NÓvOA, 1995, p. 25).

E foi na busca pelos saberes docentes do bom Professor Enfermeiro que foi solicitado aos estudantes participantes da pesquisa que escolhessem, hipoteticamente, um(a) professor(a) de seu curso como o bom Professor Enfermeiro. Apresentaram-se indagações que, para fins de análise e discussão, foram chamadas de categorias e serão apresentadas na sequência. 


\section{O que é um bom professor enfermeiro}

Os participantes da pesquisa referiram-se ao bom Professor Enfermeiro como aquele que se destaca pela forma como ensina. Figurou nas falas a relação direta entre os aspectos profissionais e os aspectos pessoais.

Para os estudantes investigados, o bom Professor Enfermeiro é reconhecido a partir das relações que são estabelecidas com o ser e o sentir, nas quais é possível incluir respostas como: "que tem empatia, que é ético, que é imparcial, que ama o trabalho, que é disponível, que é paciente, que inspira, que é uma pessoa justa, que é humilde'. Em seguida, as relações que estabelece com os conhecimentos teóricos, os quais correspondem a: 'que tem domínio do conteúdo e que se atualiza' e, por fim, as relações que estabelece com o fazer metodológico: 'que sabe ensinar/que tem didática, que esclarece dúvidas, que é organizado'.

As respostas dos estudantes relacionaram-se ao que Cunha (2012) atribui à consciência docente e à expectativa discente e social. Assim, valores como 'precisa ser responsável e honrado' e 'os alunos devem ser tratados todos iguais' correspondem a 'que tem empatia, que é imparcial, que ama o trabalho, que é disponível, que é uma pessoa justa'.

Para ilustrar os achados desta pesquisa, seguem falas apontadas pelos estudantes:

"Porque é compromissada com o conteúdo passado tanto em sala de aula como em campo de estágio, [...], é pontual com aulas, notas e estágio [...]" (A08).

"Pois ele demonstra interesse em nos ensinar, em repassar experiências reais, em nos tornar profissionais competentes e responsáveis" (A 14).

Também, os aspectos afetivos permeiam as falas dos estudantes na definição do bom Professor Enfermeiro. Para Freire (2018), a dimensão da afetividade não pode ser dissociada da docência e a admissão de que caracteres afetivos não estão excluídos da cognoscibilidade. A afetividade permeia tanto o querer bem, quanto o compromisso docente. Aspectos que os estudantes reconheceram neste estudo, como demonstra a fala de A34:

"Tem características de uma pessoa humanizada, sabe conversar e 
entender o aluno e sabe se impor diante a turma" (A34).

Assim, para Pimenta et al. (2013, p. 144), o ensino

é uma prática social complexa. Realizado por seres humanos entre seres humanos, o ensino é transformado pela ação e relação entre os sujeitos (professores e estudantes) situados em contextos diversos: institucionais, culturais, espaciais, temporais, sociais (PIMENTA ET AL, 2013, p. 144).

Há, ainda, nas falas dos estudantes, aspectos relacionados à gestão do conteúdo e a relação docente com esse. Desse modo, 'que sabe ensinar/que tem didática, que tem domínio do conteúdo, que esclarece dúvidas, que é organizado, que se atualiza', também foram respostas à indagação dessa categoria de análise.

\section{Características do bom professor enfermeiro}

Os estudantes apontaram o conhecimento, o domínio do conteúdo, a didática e a organização do professor como alguns dos atributos que 0 adjetivam 'bom'.

Riegel (2008) afirma que os Professores Enfermeiros mencionam a importância de conhecimentos específicos da área em que lecionam. Destacam também a importância da experiência e a atuação nas áreas de assistência e em funções próprias da Enfermagem, anterior ou concomitantemente ao exercício da docência, como meios para adquirir domínio dos conteúdos pertinentes ao ensino da profissão.

Nas respostas aos questionamentos, os estudantes reconhecem e demandam esse domínio ao bom professor, atribuindo a ele responsabilidade direta à docência exitosa como pode ser observado na seguinte fala:

"Excelência em lecionar, bagagem teórica ampla, [...]" (A09).

Figuram, também, no elenco das características do bom Professor Enfermeiro, termos como: 'ético, profissional, pontual, assíduo, rigoroso e justo'. Termos agrupados para a análise por pertencerem ao campo da ética profissional.

A ética, portanto, permeia o ofício do mestre e o implica. Alimentada 
não somente pela moral individual, para ela convergem e determinam os saberes múltiplos que os professores assimilam e desenvolvem em sua profissão. Para Gauthier et al. (2013), o professor necessita, em seu ofício, ter consciência de diversos fatores que demandam decisões e considerações implicadas à ética.

Portanto, à docência implica, também, a dimensão ética, e, nesse sentido, pode-se afirmar que a pontualidade e a assiduidade docente, enquanto aspectos que denotam o comprometimento do professor, correspondem a profissionalismo e, portanto, a uma postura ética.

Os estudantes atribuem ao bom Professor Enfermeiro algumas características que fundamentam as relações que estabelecem entre si. Foram apontados como bom professor os que 'tem empatia, mantém bom relacionamento, é atencioso, paciente, disponível e humilde'.

Aspectos que permeiam também os estudos de Gauthier et al. (2013), os quais afirmam que os professores com características que favorecem o bom relacionamento - que em seus estudos foram citados como solidários, calorosos, agradáveis, justos, democráticos, pessoais, simpáticos e afáveis são capazes de criar um clima de classe positivo e, assim, otimizam as condições para o aprendizado.

Os estudantes reconhecem no bom Professor Enfermeiro uma presença de apoio e confiança, como podemos observar:

"[...], estar sempre ali quando precisamos, [...]" (A18).

Os participantes do estudo referiram ainda que o bom Professor Enfermeiro é 'positivo e inspirador e que esses aspectos fomentam a evolução discente'.

Outra característica referida pelos participantes do estudo foi que o bom Professor Enfermeiro é 'esclarecedor'. Esse aspecto foi referido por eles em algumas falas, como, por exemplo:

"[...] Tirava todas as dúvidas quantas vezes fosse necessário" (A13).

"Quando nos dá segurança em que tiramos nossas dúvidas, mostrando o objetivo certo de tudo que é necessário passar ao paciente" (A19). 
Para Freire (2018), está justamente nessa demanda discente pelos esclarecimentos do professor a importância do papel do educador. Ora, concebendo uma educação para além da transmissão de conteúdos se faz imprescindível ao professor "[...] a certeza de que faz parte de sua tarefa docente não apenas ensinar os conteúdos, mas também ensinar a pensar certo" (FREIRE, 2018, p. 28).

Emergem ainda, dentre as características do bom docente, aquele que é 'experiente e atualizado'. Tais aspectos refletem na correlação que esse professor estabelece entre seus conteúdos e a assistência direta aos pacientes, e perpassam as respostas dos estudantes a todas as questões desta pesquisa.

\section{Recursos metodológicos e metodologia que o bom Professor Enfermeiro utiliza}

Quanto à metodologia do bom Professor Enfermeiro, os estudantes apresentaram como aspectos positivos: 'dinâmica, esclarecedora, didática, inspiradora, boa e atual', em detrimento da expressão 'pouco dinâmica', que também figurou como resposta a essa categoria, embora com menor expressividade.

Os participantes da pesquisa mencionam recursos metodológicos variados na dinâmica do bom professor, a saber: 'vídeos, material impresso, dinâmica, pesquisa, conversa, internet, laboratório, apresentação, socialização de conhecimentos, música, provas e visitas técnicas, havendo destaque para as aulas em projetores multimídia', referidos como datashow e power point, slide.

Acerca dos recursos metodológicos apresentados, Gauthier et al. (2013) afirmam que os professores que obtêm melhores resultados, conseguem captar a atenção dos estudantes por meio de múltiplos estímulos e recursos variados.

Algumas falas sugeriram essa atitude do bom professor:

"[...], quando vê que a sala está desanimada ou com sono uma atividade física, música" (Al1). 
"Maravilhosa, sempre uma grande troca e um grande ganho de conhecimento. Excelente manejo ao ministrar conteúdos maçantes de forma a torná-los mais didáticos" (A09).

Portanto, para além dos saberes teóricos do conteúdo, os conhecimentos sobre metodologia de ensino e os recursos que viabilizam sua aplicação constituem igualmente o roll dos saberes dos bons professores. São saberes adquiridos desde a academia e, para além dela, no próprio trabalho, os quais vão instrumentalizando os professores de macetes ou facetas, como definem Gauthier et al. (2013) e, como afirma Libâneo (2012, p. 90), "ajudam a melhor realizar o trabalho e melhorar a capacidade reflexiva sobre o que e como mudar".

Consoante ao pensamento de Gauthier et al. (2013), o estudo também evidenciou a relação da metodologia do bom Professor Enfermeiro com a 'dinamização das aulas e conteúdos, a busca por estratégias de otimizar a compreensão, o aproveitamento do tempo e da estrutura e a boa utilização e organização das avaliações', como pode-se observar nas falas a seguir:

"É bem dinâmica, conversada, sempre esclarecendo as dúvidas, traz fatos reais para a melhor compreensão" (A28).

"Aula produtiva, o tempo é muito bem aproveitado. Esclarece todas as dúvidas, sempre traz desafios para a turma" (A22).

Para Delibório (2016), a utilização de recursos digitais pelos professores enfermeiros exemplifica a dinamização das aulas e estimula o engajamento dos estudantes no aprendizado e otimiza as atividades de ensino. Para a autora, esses recursos estimulam a criatividade e a autonomia dos estudantes e, ao mesmo tempo, demandam dos professores o conhecimento e a atualização docentes para o uso das novas tecnologias.

Na pesquisa, algumas falas sinalizam a otimização do aprendizado a partir da multiplicidade de formas de apresentação de conteúdos, aspectos que ratificam a teoria das múltiplas inteligências de Gardner (1994), como pode ser observado nas seguintes falas:

"É dinâmica, divertida, uma aula leve que é mais falada, pra mim 
dessa forma aprendo muito melhor, avalia o aluno e seu conhecimento pela participação em sala de aula" (A27).

"Maravilhosa, sempre uma grande troca e um grande ganho de conhecimento. Excelente manejo ao ministrar conteúdos maçantes de forma a torná-los mais didáticos" (A09).

\section{A relação que o bom Professor Enfermeiro estabelece entre os conteúdos e a assistência de enfermagem direta ao paciente}

Quanto à relação que o bom docente enfermeiro estabelece entre os conteúdos e a assistência de enfermagem direta ao paciente, os participantes da pesquisa destacaram aspectos que permitem dividir suas respostas em três categorias. Assim, para os estudantes, os bons Professores Enfermeiros constroem essa relação baseada (a) em sua experiência profissional; (b) ensinando a humanização e (c) contemplando a correspondência entre teoria e prática.

Barato (2015) aponta que os professores da educação profissional que utilizam oficinas de aprendizagem - no caso da enfermagem, laboratórios costumam ter uma história de êxito profissional, uma vez que a ação docente é fundamenta em práticas. Assim, a experiência fundamenta seu fazer.

Os participantes do estudo reconhecem os conhecimentos do bom Professor Enfermeiro em íntima relação com a prática profissional, como fundamento e via à aplicação da teoria:

"Relação de experiência vivida no seu dia a dia de trabalho. Que para nós traz uma experiência riquíssima em sala de aula" (A22).

E nesse sentido, dialogam com o pensamento de Barato (2015) os autores Gauthier et al. (2013), os quais afirmam que os professores mais eficientes dedicam tempo ao ensino da prática, reconhecendo neste uma estratégia de ensino explícita.

Dessa forma, auxilia-nos a compreensão do porquê na presente pesquisa, para alguns estudantes, o bom Professor Enfermeiro estabelece a relação entre os conteúdos e a prática de enfermagem por meio da 
humanização. Barato (2015) ainda destaca que o ensino de valores não deve ser desvinculado do exercício profissional.

O aspecto da relação teoria e prática a partir da humanização também foi apontado:

"Estabelece a melhor relação possível, suas experiências são ótimas para termos como base o cuidar e a acima de tudo a humanização" (A32).

Nota-se que não é necessário discorrer sobre humanização, porém, as atitudes em ambiente de prática são apreendidas como parte da constituição e identidade profissional. No ensino da prática profissional, o professor pode ensinar valores, muitas vezes sem menções verbais, apenas pelo seu fazer. Nas palavras de Barato (2015): "muitas vezes, os valores não foram verbalmente anunciados, mas celebrados por meio de gestos, cuidados, olhares, avaliações compartilhadas (com outros alunos e/ou o professor)" (BARATO, 2015, p. 61).

Quanto à coerência que se desvela aos estudantes a partir da materialização dos discursos na prática docente, um participante do estudo afirma que a relação entre as teorias e a prática profissional:

"É uma relação harmoniosa, pois o que nos passa é como realmente age na assistência" (A08).

Desse modo, fundamentos teóricos e posturas requeridas ao profissional são ensinados e aprendidos no exercício da profissão e em diálogo e retroalimentação com os conteúdos teóricos, demandando a consciência do bom professor, quanto ao caráter formativo e imprescindível das relações coerentes e concretas entre os conteúdos teóricos e a prática assistencial do Técnico em Enfermagem.

\section{Como o bom professor se relaciona com a turma de estudantes}

Os participantes do estudo destacaram que a boa relação se estabelece a partir da 'empatia, do respeito e do comprometimento docente'. Por outro lado, alguns estudantes destacam que, para uma parte da comunidade discente, há dificuldades nessa relação.

As falas a seguir demonstram a percepção da empatia que 
fundamenta a relação entre o bom Professor Enfermeiro e os estudantes:

"É uma relação muito boa, com bastante parceria" (A18).

"Boa, pois além de passar conhecimento também escuta bastante os alunos, fazendo uma troca de conhecimentos" (A29).

Nesse sentido, Gauthier et al. (2013) afirmam que os bons professores propiciam um clima positivo na classe, a partir de uma postura solidária, calorosa, agradável, justa, democrática, pessoal, simpática e afável. Fatores que, segundo os autores, estimulam o aprendizado e fomentam o otimismo.

Quanto ao respeito, como fator envolvido na boa relação entre professores e estudantes, Freire (2018) oferece oportuna reflexão:

O clima de respeito que nasce de relações justas, sérias, humildes, generosas, em que a autoridade docente e as liberdades dos alunos se assumem eticamente, autentica o caráter formador do espaço pedagógico (FREIRE, 2018, p. 90).

A afirmação de Freire, tanto corrobora a menção ao respeito no discurso dos estudantes como contributo à boa relação no ambiente escolar, quanto justifica as falas dos estudantes, inclusive a menção ao respeito a partir do exemplo de que o bom Professor Enfermeiro 'sabe ouvir e dar espaço ao pensamento dos estudantes', como pode-se observar nas falas a seguir:

"Nessa época era uma relação muito boa, ela nos dava oportunidade para falar o que pensávamos e nos mostrava o porquê estava certo ou não" (A13).

"De muito respeito e seriedade, pois a pontualidade e organização aplicada por ela também é exigida" (A05).

Lima e Gomes (2012) contribuem com essa discussão, apontando que para quem a atitude do professor deve ser aquela "[...] que desenvolva a escuta, a tolerância e o respeito, com o(a) outro(a) - o igual e, sobretudo, com o diferente; [...]" (LIMA; GOMES, 2012, p. 208). Ao considerar as interações humanas, a partir das quais se realizam as ações de ensinoaprendizagem, o respeito ao educando como ser humano é imprescindível e, por isso, referida pelos participantes do estudo. 
Ao mencionar que o professor respeita porque exige aquilo que primeiramente cumpre, retoma-se Freire (2018) ao denominar coerência como ações dos professores que são pertinentes a seu discurso.

Alguns participantes, porém, mencionaram que alguns estudantes têm dificuldade na relação com o bom Professor Enfermeiro. Ao analisar os discursos, percebemos que essa dificuldade está relacionada ao rigor metodológico do professor e menos vinculada aos aspectos que embasam a boa relação pessoal. Seguem as falas:

"Boa parte gosta muito pelo fato dela ser muito disciplinada, alguns que não estão acostumados com maiores exigências não se deram bem com ela" (A08).

"Conflito com pequena parcela de alunos, pelo fato de ser justa e não favorecer" (A12).

Dessa forma, as falas dos estudantes apontam que a antipatia ou 0 conflito com o bom professor são atribuídos às exigências e ao tratamento justo que o professor dispensa aos estudantes.

Cunha (2012) e Freire (2018) auxiliam-nos a compreender esses aspectos já que, para ambos, a atuação do professor, não somente é a exposição dos conteúdos mas, sobretudo, sua postura, gestos, motivação, metodologia, possuem caráter formador e, por isso, sofrem o juízo dos estudantes.

\section{A formação do bom Professor Enfermeiro influencia na boa aula}

Os participantes do estudo afirmaram que a formação do professor influencia na boa aula, fator atribuído ao 'domínio do conteúdo teórico, à experiência e à didática'. Alguns participantes, porém, afirmaram que a constituição do professor que dá a boa aula está mais implicada ao caráter que à formação.

Para os estudantes, é pela formação que o bom Professor Enfermeiro tem domínio dos conteúdos, além de relacioná-los à experiência e, assim, estar empoderado para partilhar com os estudantes. Em suas palavras:

"Sim, a formação influencia e também a experiência em campo faz 
toda a diferença no domínio dos assuntos tanto prático como teórico" (A05).

"Sim. Pois sua experiência e conhecimento absorvidos em sua vida pode ser repassado ao aluno. Este mostra que tem muito a nos passar em seu conhecimento e vivência diária, com seus estudos e trabalho já vivenciado" (A07).

Também nos estudos de Riegel (2008) e Madeira (2006), os professores enfermeiros manifestaram a demanda pelos conhecimentos da área de ensino, ratificando a pouca formação específica - a partir de conhecimentos didáticos - em sua formação de base com vistas à atuação docente.

A qualidade e o comprometimento com a formação denotam ao professor a sua autoridade, a segurança em seu ofício, de modo a constituir uma preocupação docente, assim expressa por Freire (2018): "[...] preciso me preparar ao máximo para, de outro, continuar sem mentir aos alunos, de outro, não ter de afirmar seguidamente que não sei" (FREIRE, 2018, p. 95).

Esse aspecto é também denominado domínio do conteúdo. É importante ressaltar que tal domínio vincula-se à formação inicial e continuada e perpassa, também, a experiência, aspecto mencionado nas falas dos participantes do estudo.

Além dos saberes específicos do conteúdo, os estudantes demandam dos professores os saberes da didática, ou seja, conhecimentos específicos à docência, ao desenvolvimento de estratégias para e nas atividades de ensino-aprendizagem. Tardif (2010) auxilia a compreensão dessa expectativa discente. Para o autor,

[...] o professor ideal é alguém que deve conhecer sua matéria, sua disciplina e seu programa, além de possuir certos conhecimentos relativos às ciências da educação e à pedagogia e desenvolver um saber prático baseado em sua experiência cotidiana com os alunos (TARDIF, 2010, p. 39).

A didática figurou, no discurso dos participantes do estudo, como um conhecimento requerido ao bom Professor Enfermeiro para que este dê uma boa aula: 
"Sim, pois um bom professor sempre se aperfeiçoa para trazer o melhor aos alunos, busca formas de ensinar diferenciada, onde todos consigam ter o entendimento necessário e o aprendizado" (A01).

"Depende da didática. Acredito que é muito importante manter-se atualizado com o conteúdo e ter boa formação acadêmica, mas é necessário ter boa explicação oral e prática para repassar esse conhecimento para os alunos" (A06).

Os participantes do estudo afirmaram que o bom Professor Enfermeiro foi e é influenciado pelos seus professores. Tardif (2010) colabora com a discussão, pois, para esse autor, a formação inicial dos professores foi iniciada a partir dos primeiros anos nos bancos escolares e, assim, trata-se de uma formação prévia à acadêmica. A formação inicial, portanto, passa pela observação, pela crítica, pelas marcas que os bons professores foram deixando no estudante, que posteriormente tornou-se também docente.

Algumas falas auxiliam essa compreensão:

"Sim, para ser um bom professor ele tem que ter sido um bom aluno e para uma boa formação precisou de uma boa instituição com bom professor" (A15).

"Sim, acredito que seus professores foram mentores para sua vida" (A25).

Nesse sentido, para Freire (2018), a adesão docente à pedagogia democrática, o fomento à participação ativa do estudante e a busca pela construção ativa e participativa do conhecimento são reflexos de um professor cujos professores semearam esses valores.

Alguns participantes afirmaram que, apesar da importância da formação dos professores, o fato de serem atribuídos como bons professores, a partir de suas aulas, concerne a características pessoais que em suas percepções independe da formação. Seguem algumas dessas falas:

"Acredito que o que faz alguém ser bom na área de enfermagem, tanto em campo quanto lecionando é o seu caráter. O conhecimento e diplomas apenas fazem ele agir de forma correta (procedimentos)" (A14).

"Acredito que sim, mas isso vem muito de caráter muitas vezes têm 
professores que nem sempre tem os recursos necessários, mas sempre lutam pra crescer profissionalmente" (A17).

Gauthier et al. (2013) aproximam-se dessa análise ao afirmarem que o conhecimento de teorias e técnicas de ensino não exime o professor da tomada de decisão, do posicionamento e da responsabilidade do seu ofício. Pareceu-nos que é nesse sentido que os estudantes percebem aspectos de personalidade prévios à formação acadêmica.

Para Cunha (2012), porém, os estudantes não percebem com nitidez o quão as ações dos professores são conscientes ou não. Assim, a autora ajuda-nos a compreender por que alguns participantes não relacionam a formação às boas ações dos professores em classe.

\section{O bom Professor Enfermeiro contribui para a boa formação do estudante}

Os participantes deste estudo relatam que o bom professor contribui para sua formação 'pelo exemplo, com conhecimento, motivando, inspirando e esclarecendo dúvidas'. Destacam que o professor 'é um espelho, um exemplo de conduta profissional, um modelo e uma meta para o estudante'.

A seguir estão algumas falas que ilustram esses aspectos:

"Me mostrando o que fazer, como fazer, como não fazer. Ele está moldando excelentes futuros profissionais para a área de enfermagem" (A14).

"Contribui sendo espelho, alguém que a gente possa ter de exemplo de profissional que queremos ser" (A22).

Ao apontar que o bom Professor Enfermeiro é um exemplo a ser seguido, os participantes desse estudo referem-se a um aspecto mencionado por Cunha (2012), que atribuiu um padrão definido socialmente que denota o professor. Assim, ao afirmar que um professor é modelo, é exemplo e espelho, os estudantes atribuem a ele - mesmo que sem consciência - o atendimento de expectativas sociais e padrões esperados.

Ao mesmo tempo em que esse cabedal de características e expectativas, definidas pelo contexto social, podem nos fazer questionar a 
validade desses modelos talvez genéricos e engessados, é também Cunha (2012) que esclarece que há uma série de demandas e atribuições comuns aos professores e que, dessa forma, são úteis e válidas em qualquer tempo histórico e meio sociocultural.

Nesse sentido, Freire (2018) reafirma o exemplo do professor que aplica aquilo que discursa e, assim, testemunha ética e coerência e domínio da profissão aos estudantes. Portanto, o exemplo e a coerência são saberes requeridos pelos estudantes e validados pelas ciências da educação.

Os gestos dos professores impactam, portanto, a relação, posto que o professor é um modelo na formação. Sobre esse aspecto Freire (2018) afirma que "às vezes, mal se imagina o que pode passar a representar na vida de um aluno um simples gesto do professor. O que pode um gesto aparentemente insignificante valer como força formadora [...]" (FREIRE, 2018, p. 43).

Os estudantes apontaram também o conhecimento como a forma principal de contribuição docente para a sua formação profissional, como pode-se observar em algumas falas:

"Enriquece o conhecimento além do esperado do curso, trazendo informações e a realidade vivida por ela" (A05).

"Me ensinou a ter visão holística com os pacientes e me incentivou a buscar sempre mais conhecimento para poder argumentar sobre decisões a serem tomadas" (A06).

Nesse sentido, a pesquisa de Cunha (2012) também aponta a relação do professor com o conhecimento como fundamental na relação com os estudantes. Da mesma forma que no estudo em tela, em sua pesquisa sobre o bom professor e sua prática, Cunha destaca que os estudantes atribuíram a forma como o bom professor contribui para sua formação, nomeadamente por meio da partilha do conhecimento que possuem. Corroborando, Freire (2018) afirma que ensinar decorre de aprender.

Para Gauthier et al. (2013), além do professor ensinar conteúdos, cabe a ele incutir o gosto pelo estudo nos alunos. Fenômeno que se manifesta na presente pesquisa, evidenciado na fala dos estudantes que destacam que o 
bom professor 'além de contribuir com seu conhecimento, também estimula a buscá-lo continuamente'.

Dessa forma, a importância imputada aos conhecimentos do professor, não se detém na assimilação passiva desses pelos estudantes, porém, aproximam-se do que Freire (2018) propõe como o aprender a pensar a partir dos conhecimentos do professor, da pesquisa, da indagação, do estímulo à formação contínua.

Inclusive, os participantes do estudo referem também que o bom Professor Enfermeiro contribuiu para sua formação motivando e inspirando:

"Na forma de nos passar sabedoria, nos influenciando a sermos não apenas mais um, mas sim o diferencial fazer com amor ao próximo sempre" (A21).

Esses aspectos referidos pelos estudantes são também apresentados por diversos autores e, para Cunha (2012), relacionam-se a uma postura docente de crença nas potencialidades dos estudantes e, assim, a adoção de uma postura de quem se preocupa com a assunção do processo de aprendizado por aqueles.

Sob a ótica de uma docência próxima da realidade e necessidades dos estudantes, um outro aspecto que emergiu das falas dos estudantes foi a contribuição do bom Professor Enfermeiro para sua formação estar vinculada ao esclarecimento de dúvidas. Afirmam os participantes:

"Todas as vezes que tive dúvidas e ela teve paciência para me explicar, tive aulas em outro horário, ela sempre disposta a esclarecer minhas dúvidas" (A01).

"Ela contribui como professora pois tem domínio do assunto e como ser humano também, em alguns momentos de dificuldades minhas nos estágios ela sentou e conversou, compreensão total de uma professora que acima de qualquer coisa quer ver os alunos bem" (A27).

Chama-nos a atenção a dedicação, comprometimento e consciência da responsabilidade docente que se depreende desses relatos dos estudantes.

Atentar para o crescimento dos estudantes para além do simples 
cumprimento de cronogramas e ministração de aulas e conteúdos, conforme programação, pareceu-nos serem características dos docentes a quem os estudantes se referiram. Portanto, esse professor é, para Gauthier et al. (2013), aquele que partilha com o estudante a responsabilidade pelo seu desempenho.

Nesse sentido, Freire (2018) afirma que "a responsabilidade do professor, de que às vezes não nos damos conta, é sempre grande. A natureza mesma de sua prática, eminentemente formadora, sublinha a maneira como a realiza" (FREIRE, 2018, p. 64).

Para este autor, constitui essa maneira de realizar esse ofício a abertura ao outro, a disponibilidade, o diálogo e busca por respostas aos questionamentos. Tais condutas correspondem às descrições dos participantes do estudo, os quais afirmam que o bom Professor Enfermeiro é alguém disponível, paciente, que 'senta e conversa' ao perceber as dificuldades dos estudantes. Essas atitudes docentes são descritas por Gauthier et al. (2013):

quando o desempenho dos alunos é baixo, os professores que não somente fornecem retroações, mas ensinam de novo e dão novas tarefas a serem efetuadas aumentam as chances de os alunos dominarem melhor o que deve ser aprendido (GAUTHIER et al., 2013, p. 238).

Assim, aspectos afetivos também permeiam a percepção dos estudantes acerca do modo como o bom Professor Enfermeiro contribui para sua formação.

Nesse viés, o pensamento Freireano de que ensinar exige querer bem, certamente compreende a preocupação docente com o desenvolvimento dos estudantes e passa pelo esclarecimento e pela retomada, sempre que necessários, a partir de um olhar atento e humano do docente.

\section{Outras questões apresentadas de forma espontânea pelos participantes da pesquisa}

Os estudantes puderam, ao fim das questões roteirizadas, realizar de forma espontânea algum comentário que achassem oportuno. Desse modo, 
surgiram falas que se referiam a aspectos como reconhecimento docente, síntese sobre os saberes docentes, percepção sobre a realidade educacional, entre outros. Destacam-se, a seguir, duas falas que sinalizam aspectos que merecem a atenção da comunidade escolar.

Um estudante apresentou uma síntese sobre o que seria o bom professor: "Um bom professor deve zelar pela organização, cronograma, ser justo entre os alunos e utilizar de mais dinâmica e prática entre as aulas" (A12). Trata-se de um conceito bastante elaborado, considerando que os estudantes não têm um nível de consciência muito amplo acerca das interações subjetivas que movem as atitudes dos professores, como afirma Cunha (2012).

Pode-se afirmar que, a partir da experiência desse participante com o bom Professor Enfermeiro, este conseguiu apreender vários elementos que as teorias de educação e diversos autores que corroboram com esse estudo referem como saberes docentes pertinentes ao bom docente. Esse fator sinaliza a presença marcante de tais características na constituição e na atuação docente daquele que este aluno denominou o bom professor.

A segunda fala demonstra que os estudantes não estão alheios à realidade educacional, tampouco, ao contexto histórico social e político que vivemos: "No dia a dia na escola, estou observando que as instituições de ensino estão dando pouco valor aos professores, restringindo ações, limitando a interação professor/aluno". (A14). Esse estudante ratifica as proposições de Tardif (2010) e Cunha (2012), quando estes afirmam que o meio social e o contexto, nos quais a docência é exercida e a discência se dá, determinam o ideal do bom docente e as demandas dos estudantes.

\section{CONSIDERAÇÕES FINAIS}

O estudo demonstrou que os estudantes dos Cursos Técnicos de Enfermagem reconhecem os saberes que os professores mobilizam em seu ofício cotidiano. A partir das experiências na relação de interação entre professores e estudantes, os últimos depreendem do fazer dos mestres as características que lhes conferem a denotação de bom professor. 
Os participantes destacam que a empatia e, dessa forma, os aspectos afetivos na relação entre professores e estudantes determinam o reconhecimento do bom Professor Enfermeiro. Nesse sentido, o estudo apontou que o bom Professor Enfermeiro estabelece relações de qualidade a partir da empatia, a qual se manifesta pelo interesse com o aprendizado dos estudantes e a dedicação à docência.

Os estudantes dos Cursos Técnicos de Enfermagem mencionaram como saberes docentes no ofício do bom Professor Enfermeiro, aspectos que corroboram a revisão teórica sobre o tema. Assim, as falas dos estudantes apontaram aspectos relacionados ao saber fazer, ao saber ser, ao saber agir e aos saberes específicos à docência.

O domínio do conteúdo, a ética, a metodologia e a didática foram aspectos recorrentes nas respostas ao questionário. Destaca-se que, para os participantes do estudo, tais aspectos não foram apontados como hierarquizados, porém, em uma dinâmica de inter-relação e complementaridade, corroborando, portanto, às pesquisas anteriores.

Os professores foram apontados como produtores de saberes a partir de seu ofício cotidiano. Desse modo, a experiência e o exercício - quer da docência, quer da assistência em enfermagem - da profissão empoderam, na percepção do estudante, o professor para a tomada de decisão, para a gestão do conteúdo e da classe, além do domínio dos conteúdos e do exercício da profissão.

A formação inicial e continuada do bom Professor Enfermeiro foi mencionada como importante na constituição dos saberes docentes, sobretudo, os saberes da didática e da metodologia, embora, aspectos pessoais e da personalidade foram apontados como determinantes na postura que faz de determinado Professor Enfermeiro aquele que é considerado como bom.

A atuação do bom Professor Enfermeiro influencia positivamente os estudantes. Para os participantes desta pesquisa, o professor inspira, motiva, estimula e compartilha responsabilidades. Tal reconhecimento figurou como resposta a atitudes que foram descritas como dedicação e abertura de 
espaços para retirar dúvidas e recuperar dificuldades de aprendizado, abertura às demandas dos estudantes, ética, além do reconhecimento do arcabouço teórico, metodologia e relação que o professor estabelece entre os conteúdos e o exercício da profissão.

A pesquisa sinaliza a necessidade de ampliação dos estudos na área de formação de professores para a Enfermagem visto a escassez de publicações. Destaca-se, também, a possibilidade de serem realizados estudos comparativos entre as práticas docentes de professores com Bacharelado e professores com Licenciatura em Enfermagem, visando à ampliação das discussões acerca do que se considera o bom Professor Enfermeiro.

Embora realizada em um contexto local, destaca-se que os sujeitos da pesquisa apresentaram o que desejam em termos de processos de ensinoaprendizagem, com maturidade para destacar o que acreditam ser decisivo para o seu sucesso escolar e profissional.

Por fim, acredita-se que o grande desafio esteja em reconhecer no bom Professor Enfermeiro uma referência para os demais professores, a fim de que se desenvolvam práticas capazes de contribuir para a formação de professores e de estudantes do país.

\section{REFERÊNCIAS}

ARROYO, M. G. Ofício de Mestre: imagens e auto-imagens. Petrópolis, RJ, Vozes, 2000.

BARATO, J. N. Fazer bem feito. Valores em educação profissional e tecnológica. Brasília: UNESCO, 2015. 219 p. Disponível em: http://unesdoc.unesco.org/images/0023/002336/233600POR.pdf Acesso em: 14 mar. 2018.

BRASIL. MINISTÉRIO DA EDUCAÇÃO/MEC. Cadastro Nacional de Cursos e Instituições de Educação Superior. Cadastro e-MEC. 2018. Disponível em: http://emec.mec.gov.br/ Acesso em: 27 mai. 2018.

BRASIL. MINISTÉRIO DA EDUCAÇÃO/MEC. SisTec. Consulta Pública das Escolas e Cursos Técnicos Regulares nos Sistemas de Ensino e Cadastradas no MEC. 2019. Disponível em: http://sistec.mec.gov.br/consultapublicaunidadeensino. Acesso em: 14 mar. 2019. 
COFEN. CONSELHO FEDERAL DE ENFERMAGEM. Enfermagem em números. Quantitativo de profissionais por regional. Disponível em:

http://www.cofen.gov.br/enfermagem-em-numeros. Acesso em: 20 jan. 2020.

COREN. CONSELHO REGIONAL DE ENFERMAGEM DE SANTA CATARINA.

Consolidação da Legislação e Ética Profissional / organizadoras Denise Elvira Pires de Pires et al. 2.ed. Florianópolis: Conselho Regional de Enfermagem SC: Quorum Comunicação, 2013. 132.

CUNHA, M. I. da. O bom professor e sua prática. 24. Ed. Campinas, São Paulo: Papirus, 2012.

DELIBÓRIO, A. O ambiente virtual de aprendizagem no curso de enfermagem: ressignificando as práticas e os saberes docentes 27/06/2016 177 f. Mestrado em EDUCAÇÃO Instituição de Ensino: UNIVERSIDADE DO OESTE PAULISTA, Presidente Prudente Biblioteca Depositária: Rede de Bibliotecas da Unoeste - Campus II. Disponível em:

https://sucupira.capes.gov.br/sucupira/public/consultas/coleta/trabalhoCon clusao/viewTrabalhoConclusao.jsf?popup=true\&id_trabalho=4592279. Acesso em: 14 jun. 2018.

FREIRE, P. Pedagogia da autonomia: saberes necessários à prática educativa. 57. ed. Rio de Janeiro/São Paulo: Paz e Terra, 2018.

GARDNER, H.. Estruturas da mente. A Teoria das Inteligências Múltiplas. Porto Alegre. Artes Médicas, 1994.

GAUTHIER, C. e† al. Por uma teoria da pedagogia: pesquisas sobre o saber docente. 3. ed. ljuí: Ed. Unijuí, 2013.

LIBÂNEO, J. C. Reflexividade e formação de professores: outra oscilação do pensamento pedagógico brasileiro. In: PIMENTA, S. G.; GHEDIN, E. (Orgs). Professor Reflexivo no Brasil: gênese e crítica de um conceito. 7. ed. São Paulo: Cortez, 2012. p. 86.

LIMA, M. S. L; GOMES, M. O. Redimensionando o papel dos profissionais da educação: algumas considerações. In: PIMENTA, S. G; GHEDIN, E. (Orgs.) Professor reflexivo no Brasil: gênese e crítica de um conceito. 7. ed. São Paulo: Cortez, 2012.

MADEIRA, M. Z. de A. A prática pedagógica das professoras do Curso de Enfermagem: revisitando a construção dos saberes docentes 01/08/2006 159 f. Mestrado em EDUCAÇÃO. Instituição de Ensino: FUNDAÇÃO UNIVERSIDADE FEDERAL DO PIAUÍ, Teresina. Biblioteca Depositária: Biblioteca Comunitária Jornalista Carlos Castelo Branco. Disponível em:

http://ufpi.br/arquivos_download/arquivos/ppged/arquivos/files/dissertacao/ 2006/pratica_enfernagem-mariaz.pdf. Acesso em: 14 jun. 2018. 
NÓVOA, A. Formação de professores e profissão docente. In. Os professores e a sua formação. Nóvoa, A.(org.) 2. ed. Portugal: Publicações Dom Quixote, 1995.

RIEGEL, F. Saberes dos docentes de um curso de graduação em enfermagem e as implicações das políticas públicas de saúde e educação 01/12/2008 107f. Mestrado em EDUCAÇÃO Instituição de Ensino: UNIVERSIDADE DO VALE DO RIO DOS SINOS, São Leopoldo Biblioteca Depositária: Universidade do Vale do Rio Sinos - UNISINOS. Disponível em: http://www.repositorio.jesuita.org.br/bitstream/handle/UNISINOS/1961/Fernan doRiegelEducacao.pdf? sequence=1 \&isAllowed=y. Acesso em: 12 jun. 2018.

SGARBI, A. K. G. et al. Formação do enfermeiro para a docência no ensino técnico em enfermagem. Interfaces da Educação, Paraíba, v.6, n. 17, p. 4465. 2015. Disponível em:

http://periodicosonline.vems.br/index.php/interfaces/article/view/745/0 Acesso em: 15 nov. 2017.

SGARBI, A. K. G. Enfermeiro docente no ensino técnico em enfermagem. 2015 98 f. Dissertação (Mestrado em Enfermagem) - Universidade Federal de Mato Grosso do Sul, Campo Grande, 2015. Disponível em:

https://posgraduacao.ufms.br/portal/trabalho-arquivos/download/1790 Acesso em: 12 dez. 2017.

PINTO, Á. V. Sete lições sobre educação de adultos. 14 ed. São Paulo: Cortez, 2005.

PIMENTA, S. G. et al. A construção da didática no GT Didática: análise de seus referenciais. In: Revista Brasileira de Educação. v. 18, n. 52, janeiromarço, 2013, p. 143-241, ANPED, Rio de Janeiro; Autores Associados, Campinas-São Paulo.

TARDIF, M. Saberes docentes e formação profissional. 11 ed. Petrópolos, RJ: Vozes, 2010.

YIN, R. K. Estudo de caso: planejamento e métodos. 3 ed. Porto Alegre: Bookman, 2005.

Recebido em: 24 de outubro de 2019

Aprovado em: 29 de janeiro de 2020 